\title{
The Prediction of Perceived Level of Computer Knowledge: The Role of Participant Characteristics and Aversion toward Computers
}

\author{
David M. Compton \\ Palm Beach Atlantic \\ University, West Palm \\ Beach, FL, USA
}

David Compton@pba.edu

\author{
William H. Burkett \\ Palm Beach Atlantic \\ University, West Palm \\ Beach, FL, USA \\ William Burkett@pba.edu
}

\author{
Gail G. Burkett \\ Palm Beach Community \\ College, Lake Worth, \\ FL, USA \\ griswolg@pbcc.cc.fl.us
}

\begin{abstract}
As we move into a new century, the ability to predict the impact of computer attitudes on computer knowledge is still a key component to the understanding of information sciences. Survey data about computer knowledge, interest, and level of interest were collected from 478 students at three types of colleges - a four-year liberal arts college, a business college, and a community college. The participants included individuals who fell within three self-rated computer knowledge categories, novice $(\underline{n}=46)$, average $(\underline{n}=286)$, or expert $(\underline{n}=146)$, Stepwise discriminant function analysis was used to find the best subset of surveyed characteristics with which to discriminate among respondents with novice, average, or expert levels of computer knowledge. Two composite measures extracted from a previous analysis, reinforcement expectations for computers, and efficacy expectations for computers, and the statement, "I know how to use computer programs," were significant predictors of computer competency. Conversely, traditionally examined demographic variables such as gender and age were not significant predictors. Implications for the present findings are discussed.
\end{abstract}

Keywords : discriminant function analysis, computer aversion, computer anxiety, computer attitude

\section{Overview}

Among the requisite skills necessary for the $21^{\text {st }}$ century, computer literacy will be considered just as necessary as the ability to read, write effectively, and perform arithmetic calculations were in the $20^{\text {th }}$ century (Anderson, Bikson, Law, \& Mitchell, 1995; Hawkins \& Paris, 1997; Peterson, 1995). Through the economic, cultural, and social institutions that impact society, the so-called "computer revolution" has had and, in the future, will have an even more ubiquitous impact on the lives of individuals (Dertouzos, 1991; Schellenberg, 1994).

Certainly, one negative consequence of this revolution is a concomitant increase in a concept-specific psychological state known as anxiety toward the use of or interaction with computers (Oetting, 1983; McPherson, 1998). Past research has demonstrated that college students enter higher education with differing levels of computer know ledge (Dologite, 1987; Hawkins \& Paris, 1997; Lee,

Material published as part of this journal, either on-line or in print, is copyrighted by the publisher of Informing Science. Permission to make digital or paper copy of part or all of these works for personal or classroom use is granted without fee provided that the copies are not made or distributed for profit or commercial advantage AND that copies 1) bear this notice in full and 2) give the full citation on the first page. It is permissible to abstract these works so long as credit is given. To copy in all other cases or to republish or to post on a server or to redistribute to lists requires specific permission and payment of a fee. Contact Editor@inform.nu to request redistribution permission.
Pliskin, \& Kahn, 1994). Such differences can have a profound impact as students with less computer experience tend to be less focused, have a more negative attitude toward computers, and have demonstrably less awareness of the role of technology in their proposed career (Malaney \& Thurman, 1989-1990).

To date, no studies have been conducted using discriminant function analytic techniques to examine college student profiles in relation to computer knowledge. Therefore, the purpose of the present study was to determine what factors, if any, were predictive of perceived knowledge of computers and their operation. To accomplish this objective, students from three colleges completed an adapted version of Meier's Computer Aversion Scale (Meier, 1988, 1990), a series of demographic items, and rated their own level of computer know ledge.

\section{Method}

\section{Participants}

The participants were 579 college students (216 men and 363 women) from three colleges located in southern Florida. After exclusion of incomplete surveys, the data were analyzed for a total of 478 surveys appropriate for the present analyses. Age differences were observed among the three schools, $\underline{F}(2,565)=38.65, \mathrm{p}<.001$. Post hoc examination (Tukey, $\mathrm{p}<.05$ ) of this observation revealed that the Business College (BC) students were significantly 
older $(\underline{M}=27.79$ years, $\underline{\mathrm{SD}}=6.93$ years $)$ than students from the other schools. The means for the Community College $(\mathrm{CC} ; \underline{\mathrm{M}}=22.95, \underline{\mathrm{SD}}=7.29$ years $)$ and Liberal Arts College (LAC; $\underline{\mathrm{M}}=21.54$ years, $\underline{\mathrm{SD}}=5.60)$ were not significantly different.

All sites were Southern Association of Colleges and Schools (SACS) accredited and granted undergraduate and graduate degrees appropriate to their charters. School A was a 2-year state mandated community college (CC) granting an Associates degree, having a student population of 42,000 . It is a typical community college and thus most students are commuters, though there are a limited number of dorms available. Students have computers in numerous teaching labs and the library on each campus.

School B is a 4-year individually held private business college (BC) with a limited offering in majors. The school grants both Associate and Bachelor degrees and has a population of approximately 400 students. There are no dorms available and all students are considered commuters. Computers are available in the two computer teaching labs and library. Students included in the survey were primarily members of classes that met in the evening.

School C is a 4year liberal arts private college (LAC) with a wide range of majors and chartered to grant Associate, Bachelor and Masters degrees. The school has a population of $2800+$ with about half living on campus. Students included in the survey were members of day and evening classes in both the Bachelors and Masters programs from a number of disciplines including Arts, Education, Business, and Communications.

\section{Instrument}

The survey consisted of a series of true/false and multiplechoice questions as well as demographic items adapted by Burkett (1993) from the Computer Aversion Scale (CAV; Meier, 1988, 1990). Meier's survey was chosen for its brevity and the ability to assess three dimensions of computer use - reinforcement expectations for computers (REC), outcome expectations for computers (OEC), and efficacy expectations for computers, respectively (EEC). Factor analysis (Principle Components Analysis; PCA) with Varimax rotation of the adapted survey used in the present investigation also suggested a three-factor solution (Compton, Burkett, \& Burkett, 2001). These factors are discussed elsewhere (Burkett, Compton, \& Burkett, 2001). The internal consistencies of the resulting scales were then tested using Cronbach's alpha. Reliability analysis of these scales produced the following: $\mathrm{REC}, \mathrm{a}=.87$; OEC, a $=.77$; and EEC, $\mathrm{a}=.81$. Nunnaly (1978) has indicated .70 to be an acceptable reliability coefficient but lower thresholds (e.g., > .60) are sometimes used in the literature.
The survey, titled, "Affective and academic results of computer-based training and learning," took approximately 15 minutes to complete and, in addition to the adapted CAV questions, included a series of four questions designed to assess student perception of the efficacy of online courses. The participants were also asked demographic data related to gender, age, academic discipline, and current degree program (i.e., associates, bachelors, etc.). All surveys were completed within a one-month span in early Spring 2001 and, in the majority of instances, in the presence of the three principle authors.

Discriminant function analysis was chosen because of its conceptual relationship to both multiple regression and a one-way multivariate analysis of variance. Specifically, use of the technique allowed us to identify the attributes that best described the three computer knowledge categories and then to develop predictive tools for quick but useful identification of these groups (Silva \& Stam, 1995; Wilkinson, 1998).

The stepwise discriminant function analysis involved the consideration of four demographic variables as predictor variables. These were gender, age, major, and current type of college attended (i.e., CC, LAC, or BC). Additional potential predictors came from our adapted version of the CAV. These included the three scores from the subscales that constitute the three factors, Reinforcement Expectations for Computers (Factor I), Outcome Expectations for Computers (Factor II), and Efficacy Expectations for Computers (Factor III). Finally, four general statements designed to detect computer competency were included as potential predictor variables. The statements were, "I have taken/completed at least one on-line college course."; "I can use word processing software to write a letter."; "I know how to use computer programs."; and "A computer modem is where the computer's permanent memory is stored." Respondents were required to answer either true or false to these four statements.

\section{Scoring and Statistical Analysis}

As noted above, 101 individuals failed to complete at least one item on the survey. Of these, 26 were from the CC, 55 were from the LAC, and the remaining 20 were from the BC. Available data from these 101 individuals were not included in any of the univariate or multivariate analyses. Last, it is worth noting that group sample sizes were significantly different, ? ${ }^{2}(2)=127.99, \underline{p}<.001$.

All data were analyzed using Systat (Wilkinson, 1998). The data from the three self-rated groups were initially compared using chi-square or multivariate analysis of variance (MANOVA) as appropriate with the analyses arranged on the basis of the three factors and demographic characteristics described above. Before the results of the 
multivariate analyses were interpreted, the data were examined to determine if the appropriate multivariate assumptions were met (Stevens, 1992). The primary analysis of the present study involved the use of the multivariate technique, discriminant function analysis, as a means of predicting the three rated computer knowledge categories.

\section{Results}

All participants were classified into one of three computer knowledge categories: Novice $(\underline{n}=46)$, Average $(\underline{n}=286)$, or Expert $(\underline{\mathrm{n}}=146)$. Before submitting the demographic, factor, and knowledge scores to discriminant analysis, the data was examined to determine whether the three groups differed significantly on these quantitative and qualitative variables. Analysis of the quantitative variables revealed the following. As expected, the overall MANOVA was significant, Wilk's ? = .68, approximate $\underline{\mathrm{F}}(10,998)=$ $20.81, \mathrm{p}<.001$. Examination of the univariate analyses revealed the following. All three groups differed on Factors I, II, and III, Fs $(2,503)=52.42,3.75,94.64$, respectively, but not age.

Not surprisingly, differences in rated computer know ledge was associated with major, ? ${ }^{2}(4, \underline{N}=478)=10.16, \underline{p}<$ .05 , an observation worthy of further investigation. Differences in rated computer knowledge was also associated with school, ? ${ }^{2}(4, \underline{N}=478)=9.84, \underline{p}<.05$, with $32.03 \%$ of LAC and $28.16 \%$ of BC students rating themselves as experts. About $24 \%$ of CC students rated themselves as experts. Eighty-nine percent of CC students could use a word processing program, while $95.43 \%$ and $99.38 \%$ of LAC and BC students felt capable of using this type of computer program, $?^{2}(2, \underline{\mathrm{N}}=478)=11.72, \underline{\mathrm{p}}<.01$. Last, examination of the data revealed that perceived knowledge and location of where the computer's memory is stored were related, $?^{2}(3)=22.89, \mathrm{p}<001$. Over $48 \%$ of the individuals who rated themselves as novice agreed with the statement that a modem is where the computer's memory is stored while among those with average- or expertrated knowledge, the number of incorrect respondents dropped to $36.64 \%$ and $21.38 \%$, respectively. Thus, even among those who consider themselves as competent to expert, such knowledge may not necessarily extend to the computer hardware and the results reported below should be considered with this result in mind.

Discriminant function analysis (Systat, 1998) was used to determine which variables of the total set, if any, were capable of discriminating among respondents with self-rated novice, average, or expert levels of computer knowledge. Because the resulting discriminant function indicated significant overall group separation, the relative impact of each predictor variable was analyzed. In order to reduce the possibility of bias (Crask \& Perreault, 1977) the results of the jackknife classification matrix was used for cross- validation (Tabachnick \& Fidell, 1992). Unlike a normal classification matrix, a jackknife classification matrix excludes the data for each case as the coefficients used to assign it to one of the categories in the classification scheme are computed. The net result of this exercise is a more realistic representation of how well a set of predictor variables can separate groups. A stepwise discriminant function analysis of the data resulted in a three variable model with a correct overall classification rate of $64 \%$. The resulting discriminant function was significant, Wilk's $?=.67, ?^{2}(6, \underline{\mathrm{N}}=478)=222.15, \underline{\mathrm{p}}<.001$. The jackknife classification table is presented as Table 1 . Given the base rates of $12.5 \%, 50.4 \%$, and $37.1 \%$ expected classific ations respectively (Because there were 60 individuals who rated themselves as novices, 241 rated themselves as average, and 177 who rated themselves as expert.), the overall increase in accuracy was significant, ? ${ }^{2}(2, \underline{N}=478)=7.76$, $\mathrm{p}<.05$.

\begin{tabular}{|c|c|c|c|c|}
\hline \multicolumn{5}{|c|}{ Predicted Group Membership } \\
$\begin{array}{c}\text { Actual } \\
\text { Group }\end{array}$ & $\begin{array}{c}\text { Number } \\
\text { in Group }\end{array}$ & Novice & Average & Expert \\
\hline Novice & 46 & 22 & 17 & 7 \\
\hline & & $(48.3 \%)$ & $(37.1 \%)$ & $(14.6 \%)$ \\
\hline Average & 286 & 35 & 182 & 69 \\
\hline & & $(12.2 \%)$ & $(64.0 \%)$ & $(23.8 \%)$ \\
\hline Expert & 146 & 3 & 42 & 101 \\
\hline & & $(2.1 \%)$ & $(28.7 \%)$ & $(69.2 \%)$ \\
\hline \multicolumn{5}{|c|}{$\begin{array}{c}\text { cotion of self-rated } \\
\text { computer knowledge. }\end{array}$} \\
\hline
\end{tabular}

As shown in Table 1, the misclassification rate for novices was substantially higher than for individuals with average or expert levels of knowledge (48\% vs. 64\% \& 69\%). On the basis of bootstrap statistics (Dalgleish, 1994), the relatively large differences among the proportion of females appear to account for at least part of this discrepancy.

As can be seen in Table 2, the discriminant function separated the three groups on the Factor I (Reinforcement Expectations for Computers), Factor III (Efficacy Expectations for Computers), and the statement, "I know how to use computer programs." For both significant factors, the average score increased with the rated level of knowledge. Not surprisingly, better than $97 \%$ of both the average-rated and expert-rated respondents agreed that they knew how to 
use computer programs, while only $72.2 \%$ of the novices agreed with this statement, ? ${ }^{2}(2, \underline{N}=478)=60.66, p<$ .001. Thus, collectively, two of the factors from the modified Computer Aversion Scale and endorsement of know ledge about programs was predictive of the perceived expertise of college students.

\begin{tabular}{|l|c|c|c|c|c|}
\hline \multicolumn{5}{|c|}{ Mean Values } \\
$\begin{array}{l}\text { Vari- } \\
\text { able }\end{array}$ & $\begin{array}{c}\text { Nov- } \\
\text { ice }\end{array}$ & $\begin{array}{c}\text { Aver- } \\
\text { age }\end{array}$ & Expert & F & p \\
\hline $\begin{array}{l}\text { Gen- }_{\text {der }^{\mathrm{a}}} \\
\text { Age }\end{array}$ & .52 & .67 & .56 & 2.51 & n.s. \\
\hline Major $^{\mathrm{b}}$ & 6.46 & 6.41 & 5.94 & 0.24 & n.s. \\
\hline School $^{\mathrm{c}}$ & .85 & .64 & .58 & 2.54 & n.s. \\
\hline $\begin{array}{l}\text { Factor } \\
\text { I }\end{array}$ & 68.55 & 76.91 & 84.10 & 7.61 & .01 \\
\hline $\begin{array}{l}\text { Factor } \\
\text { II }^{\text {Fact }}\end{array}$ & 28.20 & 28.97 & 30.89 & 1.13 & n.s. \\
\hline $\begin{array}{l}\text { Factor } \\
\text { III }\end{array}$ & 33.49 & 37.89 & 44.79 & 40.63 & .001 \\
\hline $1^{\mathrm{d}}$ & .913 & .965 & .99 & 1.30 & n.s. \\
\hline $2^{\mathrm{e}}$ & .11 & .12 & .09 & 0.18 & n.s. \\
\hline $3^{\mathrm{f}}$ & .76 & .96 & .99 & 9.93 & .01 \\
\hline $4^{\mathrm{g}}$ & .46 & .37 & .20 & 0.91 & n.s. \\
\hline
\end{tabular}

Table 2. Results of the discriminant function analysis. Notes. ${ }^{a} 0=$ female, $1=$ male. ${ }^{b} 1=$ social sciences, $2=$ physical sciences, $3=$ math, $4=$ computer sciences, $5=$ business, 6 = professional studies (e.g., premed), $7=$ physical education, $8=$ fine arts, $9=$ humanities. These categories were coded for discriminant function analysis. ${ }^{c} 0=B C, 1=C C, 2=L A C .{ }^{d} 0=$ true, $1=$ false $.{ }^{e} 0=$ true, $1=$ false. ${ }^{f} 0=$ true, $1=$ false. ${ }^{g} 0=$ true, $1=$ false.

Table 3 is a presentation of the canonical analysis and associated discriminant functions. As it relates to separation of the groups, the importance of the two canonical variables (i.e., $Z_{1} \& Z_{2}$ ) is reflected in their eigenvalues, here .426 and .077 , respectively. $Z_{1}$ accounts for $84.69 \%$ and $Z_{2}$ accounts for $15.31 \%$ of the between-groups separation. Thus, as Table 3 shows, both make a significant contribution to intergroup separation. Last, examination of the canonical correlations in Table 3 reveals that the first ca- nonical variable $\left(\mathrm{Z}_{1}\right)$ is strongly related to Factors I and III $(\underline{\mathrm{rs}}=.959 \& .711$, respectively) and is moderately related to the statement that, "I know how to use computer programs." $(\underline{r}=.397)$. The second canonical variable $\left(\mathrm{Z}_{2}\right)$ only correlates with the "I know how..." statement $(\mathrm{r}=$ $.867)$.

\section{Discussion}

Discriminant function analysis, although considered a useful tool for investigating group differences, can result in some interpretation ambiguities (Tabachnick \& Fidell, 1992). However, jackknife techniques are considered robust often ameliorating interpretive difficulties (see Result section; see also, Dalgleish, 1994).

As noted above, computer literacy in the $21^{\text {st }}$ century will become more and more of a necessity (Anderson et al., 1995) and is cons idered a prerequisite for a number of careers or college programs (Furste-Bowe et al., 1995-1996). Those individuals unaware of or not exposed to the myriad of exciting uses for computers may find themselves to be part of what has been termed a technological underclass (Mestre, 2000). Certainly, students who are competent with a variety of productivity tools (e.g., word processors $\&$ spreadsheets) and have a wealth of information accessible on the internet will be at a competitive advantage relative to students who will have to expend considerably more energy mastering computer software or completing tasks in a more inefficient, manual way.

While $38 \%$ of households with income of less than $\$ 30,000$ were on-line by December of 2000 , that number had increased from $28 \%$ six months earlier (Rainie, February, 2001). However, approximately $82 \%$ of families with incomes exceeding \$75,000 were on-line. Women now exceed the number of men on-line and, in the last half of 2000 alone, a growth rate among African-American users of $22 \%$ was observed. Last, most Internet users continue to utilize "narrowband" (e.g., phone lines) services rather than broadband (e.g., DSL) services (General Accounting Office, 2001).

Compared to the past, today's college student typically enters college at least somewhat better prepared to use computers and may have a substantial amount of experience (Karsten \& Roth, 1998). In fact, although the results are not unequivocal, almost any type of prior computer experience, including video game experience, has a positive impact on computer literacy (Brock, Thomsen, \& Kohl, 1992). Unfortunately, past experience with computers is not necessarily associated with successful performance with a computer, particularly at the college level (Karsten \& Roth, 1998; Larson \& Smith, 1994). 


\begin{tabular}{|c|c|c|c|c|c|c|c|c|c|c|c|c|c|}
\hline \multirow[t]{2}{*}{ ڤँ } & \multicolumn{3}{|c|}{$\begin{array}{l}\text { Unstandardized } \\
\text { Regression Coeffi- } \\
\text { cients }\end{array}$} & \multirow[t]{2}{*}{ 可 } & \multirow[t]{2}{*}{$\%$} & \multirow[t]{2}{*}{ 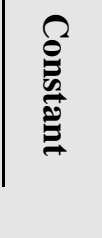 } & \multirow[t]{2}{*}{$\mathbf{p}$} & \multicolumn{3}{|c|}{$\begin{array}{l}\text { Standardized Re- } \\
\text { gression Coefficients }\end{array}$} & \multicolumn{3}{|c|}{$\begin{array}{c}\text { Correlation } \\
\text { between Predictors } \\
\text { \& Canonical } \\
\text { Variables }\end{array}$} \\
\hline & $\mathbf{X}_{1}$ & $\mathbf{X}_{2}$ & $\mathbf{X}_{3}$ & & & & & $\mathbf{X}_{1}$ & $\mathbf{X}_{2}$ & $\mathbf{X}_{3}$ & $\mathbf{X}_{1}$ & $\mathbf{X}_{2}$ & $\mathbf{X}_{\mathbf{3}}$ \\
\hline $\mathrm{Z}_{1}$ & .032 & .131 & .350 & .426 & 84.7 & -.798 & .001 & .304 & .786 & .076 & .959 & .711 & .397 \\
\hline $\mathrm{Z}_{2}$ & .025 & -.098 & 4.55 & .077 & 15.3 & -2.39 & .001 & .241 & -.586 & .986 & -.163 & .206 & .867 \\
\hline
\end{tabular}

Table 3. Canonical Analysis

A number of variables have been identified that appear to be predictive of computer anxiety inclu ding age, gender, and prior experience (Anderson, 1996; Morris, 1996-1997) but, interestingly, not keyboarding skills (Hemby, 1999). Although some research has suggested that personality characteristics of the user are correlated with computer anxiety (see Mauer, 1994, for a review), in other investigations no such correlation was detected (e.g., McPherson, 1998). Nonetheless, as McPherson pointed out, this relationship may exist in specific contexts such as in business, education, or science courses. Within the context of the present report, learning style may be an important predictor variable worthy of future inclusion. Future research should examine in a more substantive fashion additional variables with predictive utility. Further, the interrelationships among these variables, as a way of developing more fruitful predictive models, requires addition examin ation.

\section{References}

Anderson, A. A. (1996). Predictors of computer anxiety and performance in information systems. Computers and Human Behavior, 12, 61-77.

Anderson, R. H., Bikson, T. K., Law, S. A., \& Mitchell, B. M. (1995). Universal access to e-mail: Feasibility and societal implications. Santa Monica, CA: Rand Corporation.

Burkett, W. H. (1993). A study of computer aversion factors and their effect on an older adult population's computer anxiety. Unpublished Dissertation report to Nova University. http://faculty.pbac.edu/burkettw/diss whb.htm

Burkett, W. H., Compton, D. M., \& Burkett, G. G. (2001). An examination of computer attitudes, anxieties, and aversions among diverse college populations in the new millennium. Informing Science Journal, 4, 77-85 online at http://informingscience.org/Articles/Vol4/v4n3077-085.pdf

Compton, D., Burkett, W. H., \& Burkett G. G. (2001). Factor structure of the adapted Computer Aversion Survey (CAV) of Meier, 1990. http://faculty.pbac.edu/Callisto/Research/Factor_1.html

Crask, M. R., \& Perreault, W. D., Jr. Validation of discriminant analysis in marketing research. Journal of Marketing Research, 14, 60-68.
Dalgleish, L. I. (1994). Discriminant analysis: Statistical inferences using the jackknife and bootstrap procedures. Psychological Bulletin, 116, 498-508.

Dertouzos, L. (1991). Communications, computers and networks. In K. Shellenberg (Ed.), Computers in society (pp. 6-12). Guilford, CT: Dushkin.

Dologite, D. G. (1987). Measuring microcomputer literacy. Journal of Education Technology Systems, 16, 29-43.

Furste-Bowe, J., Boger, C., Franklin, T., McIntyre, B., Polansky, J., \& Schlough, S. (1995-1996). Journal of Research on Computing in Education, 28, 175-188.

General Accounting Office (2001). Telecommunications: Characteristics and choices of internet users (GAO Publication No. GAO-01-345). Washington, DC: United States General Accounting Office.

Hawkins, R. \& Paris, A. E. (1997). Computer literacy and computer use among college students: Differences in black and white. Journal of Negro Education, 66, 147-158.

Hemby, K. V. (1999). The impact of keyboarding on computer anxiety in end users. Office Systems Research Journal, 17, 9-18.

Karsten, R., \& Roth, R. M. (1998). The relationship of computer experience and computer self-efficacy to performance in introductory computer literacy courses. Journal of Research on Computing in Education, 31, 14-24.

Larson, J., \& Smith, M. A. (1994). An assessment of the computer literacy and computer attitudes of incoming first-year students at the University of Wisconsin-Eau Claire. In M. R. Simonson, N. J., Maushak, \& K. L. Abu-Omar (Eds.), Proceedings of selected research and development presentations, 1994 national convention of the Association for Educational Communications and Technology (pp. 357-366). Washington: Association for Educational Communications and Technology.

Lee, D. M. S., Pliskin, N., \& Kahn, B. (1994). The relationship between performance in a computer literacy course and students' prior achievement and knowledge. Journal of Computing Research, 10, 63-77.

Malaney, G. D., \& Thurman, Q. (1989-1990). Key factors in the use and frequency of use of microcomputers by college students. Journal of Education Technology Systems, 18, 151-160. 
Maurer, M. M. (1994). Computer anxiety: Correlated and what they tell us: A literature review. Computers in Human Behaviors, 10, 369-376.

McPherson, B. (1998). An analysis of personality types and computer anxiety among students enrolled in microbased computer literacy. Office Systems Research Journal, 16, 21-31.

Meier, S.T. (1988). Predicting individual differences in performance on computer-administered tests and tasks: Development of the Computer Aversion Scale. Computers in Human Behavior, 4, 175-187.

Meier, S. T. (1990). Construct validity of an instrument designed to measure computer aversion. Presented at the 1990 annual convention of the American Psychological Association. ED328569.

Morris, D. C. (1996-1997). Ownership, use, and non-use of personal computers by older adults. Journal of Educational Technology Systems, 25, 5-12.

Nunnaly, J. (1978) Psychometric theory. New York: McGraw-Hill.

Oetting, E. R. (1983). Oetting's Computer Anxiety Scale (COMPAS). Ft. Collins, CO: Rocky Mountain Behavioral Science Institute, Inc.

Peterson, T. (1995, December 25). Business week. Business Week, p. 49.

Rainie, L. (Director) (2001, February). More online, doing more. (Available from the Pew Internet \& American Life Project, 1100 Connecticut Avenue, Suite 710, Washington, DC 20036)

Schellenberg, K. (1994). Computers in society. Guilford, CT: Dushkin.

Stevens, J. (1992). Applied multivariate statistics for the social sciences $\left(2^{\text {nd }}\right.$ ed.). Hillsdale, NJ: Erlbaum.

Silva, A. P. D., \& Stam, A. (1995). Discriminant analysis. In L. G. Grimm \& P. R. Yarnold (Eds.), Reading and understanding multivariate statistics (pp. 277-318). Washington: American Psychological Association.

Tabachnick, B. G., \& Fidell, L. S. (1992). Using multivariate statistics $\left(2^{\text {nd }}\right.$ ed.). New York: Harper-Collins.

Wilkinson, L. (1998). Systat (version 9.0). Chicago: SPSS, Inc.

\section{Biographies}

David Compton, Ph.D. David Compton is Chair and Associate Professor of Quantitative Methods at Palm Beach Atlantic University. He serves as chair of the Office of Academic Research, with oversight governing all human and animal research activities. He has presented at conferences and published a number of articles in referred journals in such diverse areas as education, neuroscience, aging, neurops ychology, and contemporary social issues. He

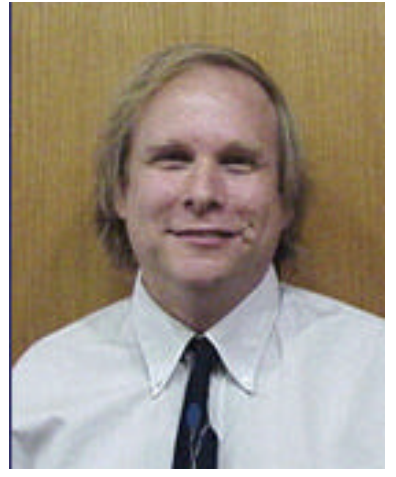

is a member of two ac ademic honor societies, Psi Chi and Sigma Beta, and a member of the New York Academy of Sciences and the Southern Society for Philosophy and Psychology.

William H. Burkett, Ph.D. serves as Assistant Professor of Computer Information Systems at Rinker School of Business at Palm Beach Atlantic University http://faculty.pba.edu/burkettb, co-editor of 'The Awakenings', PBAU's peer reviewed journal, and president of the Palm Beach Atlantic College chapter of Sigma Beta Delta National Honor Society in Bus iness, Management, and Admin istration. He is active in research in computer anxiety, computer based training and learning, and piloted peer to peer collaborative learning $\left(\mathrm{P}^{3} \mathrm{CL}\right)$. Formerly, he was Systems Manager, State of Florida, Marine Supervisor of Offshore Seismic Ve ssels, and Safety Engineer, Teledyne Exploration, Inc., and Petty Officer First Class; United States Coast Guard. He is a member of the Association for Computing Machinery; American Association for Artif icial Intelligence, and Association of Information Technology Professionals.

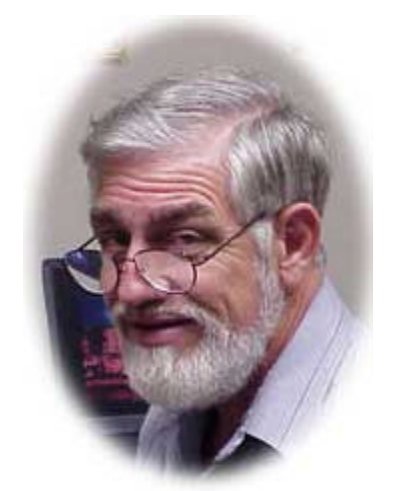

Gail Griswold Burkett, M.Sc., is an Associate Professor of CPI Math at Palm Beach Community College and serves as Cluster Chair of Palm Beach Community College CPI and is active in the development and implementation of the Center for Personalized Instruction, mathematics program. Formerly she was Educational Program Manager, State of Florida, and Chapter President of the Florida Council on Crime and Delinquency, and presented with the Correctional Educational Directors Award, 1989. She

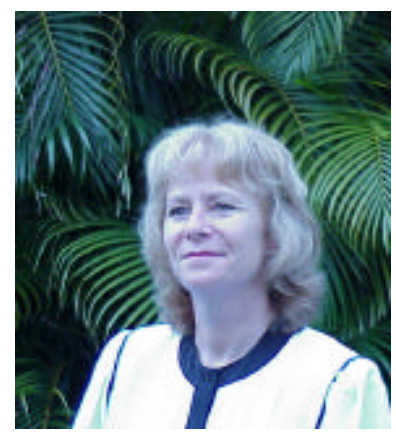
is active in research in computer anxiety, computer based training and learning, cooperative learning, and math pedagogy. She is a member of the Florida Developmental Education Association, Florida Association of Community Colleges, NADE, and United Faculty of Florida. 